\title{
POLITICA Y NEGOCIOS: \\ EN TORNO A LAS «MEMORIAS» \\ DE CAMBO
}

GUILLERMO GORTAZAR

UNED

La reciente publicación de las Memorias de Francisco Cambó (1876-1936) en Alianza Editorial y una nueva biografía escrita por Ignacio Buqueras en Plaza y Janés, en su colección de Biografías y Memorias, ha reactualizado la figura de uno de los principales protagonistas de la vida política y económica española del primer tercio del siglo $\mathrm{xx}$.

Desde el punto de vista de la historia política, las Memorias constituyen lectura obligada, en particular en lo que se refiere a la explicación de la forma en la que el nacionalismo moderado catalán, el catalanismo, supo convertirse en una poderosa y constructiva palanca de gobierno y de canalización del sentimiento nacionalista. En otras palabras, en las Memorias de Cambó se encuentra la explicación de muchos de los aspectos básicos que constituyen el núcleo central de la actual experiencia del nacionalismo catalán.

Estas Memorias, escritas poco antes de su muerte en 1947, destacan sobre las de sus contemporáneos por su nitidez, sinceridad y capacidad de análisis. El conde de Romanones escribió sus memorias, Notas de una vida, básicamente antes de 1931, cuando muchos de los protagonistas ejercían todavía responsabilidades de gobierno, y por ello carecen de perspectiva y adolecen de ambigüedad y omisiones piadosas. Las memorias de Juan de la Cierva, de Dámaso Berenguer y del marqués de Hoyos (por citar sólo las de los políticos monárquicos) se mueven en el terreno del descargo de las propias responsabilidades ante la caída de la Monarquía en 1931 y no logran superar una cierta sensación de inmediatez. Lejos de ello, las Memorias de Cambó destacan por su capacidad de análisis, junto con grandes dosis de apasionamiento y de egocentrismo. Y es que Cambó (al igual que el conde de Romanones o Santiago Alba) era un político profesional, no un aficionado. Sentía la política con pasión, con vocación, y consigue transmitir al lector la información precisa para que éste entienda en qué consiste eso tan peculiar y legítimo que es la ambición política, la ambición de mando al servicio de un ideal.

Las Memorias recogen detalladamente la forma en que Prat de la Riba y Cambó entendieron y diseñaron el modo de integrar el sentimiento naciona- 
lista catalán con la política general española. A diferencia del nacionalismo vasco de origen sabiniano, Prat de la Riba y Cambó defendieron una versión moderada del nacionalismo, inspirada en parte en el modelo checoslovaco de la época del Imperio austro-húngaro. Un nacionalismo, el catalanismo, que padeció fuertes embates desde posiciones intransigentes del resto de España, pero también por parte del nacionalismo radical de la Esquerra Republicana. Prat de la Riba y Cambó, sin renunciar al concepto de nación, de nacionalidad, asumieron y defendieron que no había contradicción en hacer política catalana y contribuir desde Cataluña a la modernización general de España. Sobre esa idea básica se atrajeron a la burguesía, a los profesionales, comerciantes y propietarios de Cataluña, construyendo una fuerza política y electoral de primera magnitud, la Lliga. Partido que, al igual que el lerrouxismo, se fundamentaba en un concepto moderno de organización y movilización de masas que muy pronto se mostró mucho más dinámico, operativo y eficaz que los viejos sistemas caciquiles utilizados por los partidos dinásticos. Ahora bien, en mi opinión, vista la experiencia desastrosa en que se zambulló nuestro país en 1923 y en 1936, hay que reconocer que el «anticaciquismo» de Cambó podía tener sentido en Cataluña porque la Lliga constituía una alternativa. Pero el empeño de Cambó por destruir el turno por falso en el resto de España, cuando todavía no se había construido un sistema de partidos moderno que posibilitara la transición del liberalismo decimonónico a un régimen liberal democrático, resultó en el fondo un debilitamiento general del sistema político. Lo cual también recuerda, en parte y salvando las distancias, el efecto disolvente que llevaron a cabo los checos en el Imperio austro-húngaro entre 1890 y 1914.

Realmente, Cambó es un personaje muy bien tratado por la historiografía. En efecto, mientras otros destacados políticos y hombres de negocios de la Restauración o no poseen aún estudios biográficos o tienen tan sólo algunas breves semblanzas, la vida de Cambó ha generado varias monografías. Eugenio D'Ors escribió una primera semblanza en 1906, El noucentisme d'En Cambó. Posteriormente siguieron otras del mismo D'Ors (1907); de Azorín, en sendas crónicas «Cambó y Canalejas» y «La nueva oratoria» (1908), y otras de Juan Maragall, Ramiro de Maeztu, Luis Sirval y Rafael Marquina. En la mayor parte de los casos eran breves crónicas, entrevistas o breves semblanzas como las que se hacían prácticamente de todos los ministros o «ministrables». Pero la primera biografía de Cambó propiamente dicha se debe a Josep $\mathrm{Pla}$ (a mi juicio, nuestro más atinado y profundo retratista biográfico) en 1931: Vint-icinc anys de política catalanista. L'Obra de Cambó. Este libro en realidad era una recopilación de materiales publicados por Pla entre 1928 y 1931 y están redactados en el estilo plutarquiano del escritor ampurdanés. El Cambó de Josep Pla no posee, por supuesto, una perspectiva global por lo temprano de 
su publicación, ni tampoco un sólido soporte documental de archivo, pero tiene el enorme valor del testimonio directo, contemporáneo y de sus intuitivas reflexiones.

Después del libro de Pla, salvo algunas crónicas y artículos sobre la vida y la obra de Cambó, se produce un vacío editorial hasta 1952. En esa fecha el prolífico Maximiano García Venero publicó La vida de Cambó, con un prólogo de Gregorio Marañón. Este libro ha pasado bastante inadvertido porque, por las mismas fechas, Jesús Pabón publicó el primer volumen de su monumental Cambó (Barcelona, Alpha, 1952), eclipsando por completo la biografía de García Venero. Pabón completó la biografía de Cambó en 1969, y, como es sabido, había tenido acceso al manuscrito de las Memorias de Cambó, que ahora su familia (según testimonio de su yerno, Ramón Guardans) ha querido publicar una vez instaurada y consolidada la democracia en España. La obra de Cambó (la edición catalana incluye dos tomos más de Diarios entre 1936 y 1946) apareció en su primera edición en catalán en 1981, y resulta evidente que Pabón siguió de forma bastante fidedigna los criterios, manifestaciones y sistemática de las memorias de Cambó.

El libro de Ignacio Buqueras, Cambó (Barcelona, 1987), ha visto la luz apenas tres meses después de la edición de las Memorias en castellano por Alianza, en traducción de Ramón Guardans. Del libro de Buqueras puede decirse que, como intento de divulgación de la figura de Cambó, puede resultar útil toda vez que, quizás, exista un público más inclinado a leer una mala biografía que unas espléndidas memorias. Pero ahí comienza y finaliza su interés, ya que, conociendo un poco la época y la figura de Cambó, se llega pronto a la conclusión de que este libro se ha escrito muy rápidamente y tal parece una obra de encargo. Ignacio Buqueras no aporta nada nuevo. No ya en el terreno de la documentación, sino tan siquiera en el de la interpretación o síntesis. Y no se trata de una crítica a una eventual tarea de divulgación, que muchas veces es muy difícil y meritoria. Se trata de que este libro, lejos de suponer una integración y explicación de lo mucho que se conoce y se ha publicado sobre Cambó, es un mero «corta y pega» de trozos de libros ya publicados. En él hay páginas enteras tomadas textualmente de otros libros y largas citas mezcladas sin ningún criterio más allá de la acumulación y la hagiografía.

Desde el punto de vista de la historia económica, Cambó posee una doble dimensión de extraordinario interés que se puede apreciar perfectamente en sus Memorias. Por un lado, su dimensión pública en la gestión al frente del Ministerio de Hacienda y los debates parlamentarios sobre el presupuesto, en particular su enfrentamiento con los planes fiscales y presupuestarios de Santiago Alba. Y, por otro lado, la dimensión privada, el espectacular proceso de enriquecimiento personal que llevó a Cambó a convertirse en una personalidad 
europea de las finanzas. No se conocen cifras precisas, pero la fortuna de Cambó debió alcanzar sumas fabulosas para la época, ya que, después de 1921, cerró su bufete de abogado de Barcelona y en adelante pudo dedicarse, entre otras cosas, a su costosa afición de coleccionista de obras de arte.

Cambó explica en sus Memorias cuál fue su relación con el mundo de los negocios: «... hasta bien entrado el año 1920, mi fortuna era tan modesta que no alcanzaba a lo que, en dinero, heredé de mi madre en 1909. Entre los años 1916 y 1920 , mis gastos habían sido mayores que mis ingresos y mis reservas estaban a punto de agotarse». Cambó dedica un largo epígrafe a relatar cómo había ejercido el oficio de abogado en el sentido del arbitraje y asesoramiento a empresas y particulares. El político catalanista trató en lo posible de evitar los pleitos, que detestaba, y en la eventualidad de que hubiera que llegar a los tribunales cedía el asunto a sus pasantes.

En otro extenso epígrafe, Cambó nos hace interesantísimas «confidencias sobre mi fortuna», en el que nos relata, entre otras muchas cosas, su papel en la CHADE (Compañía Hispano-Americana de Electricidad) y su proceso de enriquecimiento: «durante muchos años fue cosa corriente atribuirme grandes aptitudes para ganar dinero lícitamente y con poco esfuerzo. $\mathrm{Ha}$ sido ésta una pura leyenda que tomó su origen en la constitución de la CHADE y la adquisición por ésta de empresas eléctricas situadas en América del Sur. Ni la operación fue concebida y llevada a términos exclusivamente por mí ni su éxito fue debido a ninguna aptitud especial de los que fuimos sus autores, sino al hecho de la baja de fletes y combustibles que se inició dos años después de acabar la Primera Guerra Mundial y continuó hasta dos años antes de que estallara la Segunda».

La CHADE fue una empresa alemana domiciliada en España para evitar ser embargada por los aliados después de la Primera Guerra Mundial en concepto de reparaciones de guerra, y su objeto social era la producción de energía eléctrica, fundamentalmente en Buenos Aires. La Sociedad se constituyó en Madrid, en 1920, con un capital social de 120 millones de pesetas, cifra elevadísima para la época, si bien la mitad de las acciones procedían de la empresa originaria alemana. El cerebro de la operación financiera fue Dannie Heinemann, ingeniero y financiero norteamericano afincado en Europa, quien conocía perfectamente las ventajas de domiciliar esta empresa en España. Heinemann poseía experiencia de negocios en Cataluña, pues el grupo financiero al que pertenecía, Sofina, había adquirido la Compañía de Tranvías de Barcelona. El hecho es que, sin contar con un capital inicial de importancia, Cambó participó en la operación y ocupó la vicepresidencia del Consejo de Administración de la nueva compañía de electricidad. El modo concreto en que lo consiguió forma parte del secreto del sumario que ni Cambó revela en sus Memorias ni nos lo ha contado ninguno de sus numerosos biógrafos. Jesús 
Pabón se ocupó, lógicamente, del origen de la fortuna de Cambó y, a falta de documentación precisa, hace una deducción que se podría definir como la tesis de la «confianza e influencia». Tesis que sólo una profunda y ulterior investigación sobre la actividad empresarial de Cambó podrá confirmar o rebatir. Pabón, al explicar el tema de la CHADE, señala: «La intervención de Cambó -el planteamiento e invitación hechos al político español- suele explicarse por casualidades sorprendentes o por casualidades minúsculas, imposibles de comprobar. Hay otras realidades registrables y sencillas. Heinemann conocia España desde 1905; venía consultando hacía tiempo a Cambó como abogado, en relación con los asuntos que tenía en España, y había seguido con explicable atención la brillante actividad del político catalán. Entre las entidades alemanas que controlaban la DUEG - Deutsche Bank y la AEG-, la representada por Walther Rathenau hubo de ser oída en todo; y la estimación y el afecto mutuos entre Rathenau y Cambó eran firmísimos. La importante posición política de Cambó y su capacidad de gestión demostrada como gobernante eran conocidas por cuantos, pensando en España, discurrían sobre sus hombres. En definitiva, la primera cuestión era la confianza de la DUEG (la filial de la AEG en América), especialmente de sus elementos alemanes, y éstos la tenían en Cambó y en aquellas entidades y personalidades españolas que él podía normalmente requerir.»

A partir de su posición en la CHADE, Cambó encontró toda suerte de facilidades para ampliar su campo de inversiones, y gracias a sus relaciones internacionales con el grupo Sofina se le abrieron las puertas de inversiones europeas de envergadura. Así, en 1929 se constituyó, en Madrid, COGECO (la Compañia General del Corcho) con un capital de 100 millones de pesetas. El Consejo de Administración estaba presidido por Cambó, quien pasó de ese modo a controlar el más importante consorcio del corcho de Europa. En efecto, COGECO había absorbido a veintiuna compañías del corcho, catorce de las cuales eran alemanas, belgas e italianas y siete españolas.

Su fortuna le permitió afrontar con tranquilidad e independencia la actividad política, ya que, como él mismo recuerda: «era lo suficientemente grande que me proporcionaba ingresos muy superiores a mis gastos y me permitía satisfacer algunas ilusiones de mi espíritu. Me puso en situación de poder hacer política sin que las preocupaciones de orden material me distrajeran». Y es en el terreno de la economía política en el que Cambó se explaya en sus Memorias: «En lo que yo he sentido y por lo que tengo especiales aptitudes ha sido por la economía política y las finanzas públicas, y no en el aspecto teórico del intelectual, sino en el aspecto práctico del político.» Y, sin duda, las $M e$ morias resultan muy reveladoras en lo que respecta a su experiencia como ministro de Fomento y de Hacienda y nos resaltan, más allá de los aspectos públicos y conocidos, sus íntimas motivaciones en terrenos tan diversos como 
la política de personal, el déficit, los aranceles, la reforma tributaria o la Ley de Ordenación Bancaria. Donde las Memorias alcanzan un particular tono de apasionamiento es en el tema de su enfrentamiento con Santiago Alba, que se debía a una amplia confluencia de factores: rivalidad personal de dos políticos empeñados en conseguir posiciones nacionales de liderazgo, y particularmente la presidencia del Consejo de Ministros, diferente concepto de la relación centralismo-regionalismo y puntos de vista opuestos en el tema de las reformas y modernización de la Hacienda Pública. En suma, las Memorias de Cambó poseen la virtud de resultar una lectura entretenida para cualquier aficionado a la Historia, a la vez que una herramienta de uso obligatorio para el especialista en la historia política o económica del primer tercio del siglo xx. 